\title{
BMJ Open Effect of adherence to antihypertensive medication on stroke incidence in patients with hypertension: a population-based retrospective cohort study
}

\author{
Hyo Jung Lee, ${ }^{1,2}$ Sung-In Jang, ${ }^{2,3}$ Eun-Cheol Park ${ }^{2,3}$
}

To cite: Lee HJ, Jang S-I, Park E-C. Effect of adherence to antihypertensive medication on stroke incidence in patients with hypertension: a population-based retrospective cohort study. BMJ Open 2017;7:e014486. doi:10.1136/ bmjopen-2016-014486

- Prepublication history and additional material are available. To view these files please visit the journal online (http://dx.doi. org/10.1136/bmjopen-2016014486).

Received 28 September 2016 Revised 11 April 2017 Accepted 21 April 2017

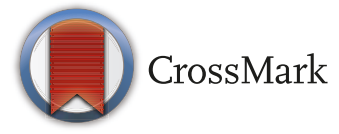

${ }^{1}$ Department of Public Health, Graduate School, Yonsei University, Seoul, Republic of Korea

${ }^{2}$ Institute of Health Services Research, Yonsei University College of Medicine, Seoul, Republic of Korea

${ }^{3}$ Department of Preventive Medicine, Yonsei University College of Medicine, Seoul, Republic of Korea

Correspondence to Eun-Cheol Park; ecpark@yuhs. ac

\section{ABSTRACT}

Objective High blood pressure is a modifiable risk factor for stroke, but non-adherence to antihypertensive medication is a growing concern for healthcare providers in controlling blood pressure. This study aimed to investigate the effect of adherence to antihypertensive medication on stroke incidence.

Design Retrospective cohort study.

Setting We analysed National Health Insurance claim data and check-up data from 2009 to 2013.

Participants 38520patients with hypertension were defined as those diagnosed with hypertension and prescribed antihypertensive medication.

Interventions No interventions were made.

Outcome measure Poisson regression analysis using generalised estimating equations models was performed to examine the association between adherence to antihypertensive medication and stroke incidence. Results Among 38520 patients with hypertension, 957 (2.5\%) strokes occurred during the study period. Nonadherence to medication was significantly associated with a higher risk of stroke (intermediate adherence: adjusted relative risk (aRR) $=1.13,95 \% \mathrm{Cl}=1.06$ to 1.21 ; poor adherence: $\mathrm{aRR}=1.27,95 \% \mathrm{Cl}=1.17$ to 1.38 ).

Conclusions Non-adherence to antihypertensive medication in patients with hypertension was associated with an increased risk of stroke. Therefore, healthcare providers need to focus on interventional strategies to ensure that these patients adhere to medication therapy and to provide continuing support to achieve longterm adherence, ultimately minimising negative health outcomes.

\section{INTRODUCTION}

Stroke is responsible for 6.7 million $(12.1 \%$ of total) deaths per annum worldwide, and is the second most common cause of death after ischaemic heart disease. ${ }^{1}$ In South Korea, 24486 per 100000 individuals $(9.1 \%)$ die of cerebrovascular diseases, making it the third most common cause of death following cancer and heart disease. ${ }^{2}$ This public health problem is expected to
Strengths and limitations of the study

This study reflects individual characteristics related to stroke, such as family history of stroke and economic status.

- We indirectly measured adherence to antihypertensive medication based on administrative claim data, which may not reflect the correct adherence.

- This study may include selection bias as check-ups in South Korea are voluntary and may be provided by private hospitals rather than by National Health Insurance.

persist or increase worldwide, including in South Korea, due to continuing industrialisation, unhealthy lifestyles and an ageing population ${ }^{3}{ }^{4}$. The most effective way to reduce the socioeconomic burden of stroke is through preventive treatment of modifiable risk factors. ${ }^{5}$

High blood pressure is one such modifiable risk factor ${ }^{6}$. According to previous studies, hypertensive treatment reduces the incidence of stroke by $30 \%-40 \%^{8}$. Thus, hypertension control and the prevention of associated morbidity and mortality should be achievable. ${ }^{10}$ To do so, international and national guidelines have recommended screening, treatment and control of high blood pressure. ${ }^{11-14}$ However, the prevalence of uncontrolled hypertension remains greater than $50 \%$ despite South Korea having higher rates of hypertension awareness, treatment and control than the global average $\mathrm{e}^{1516}$ (figure 1).

Therefore, it is important for healthcare providers to encourage patient adherence to hypertensive treatment. Adherence to hypertensive treatment is defined as the extent to which patients take medications, 


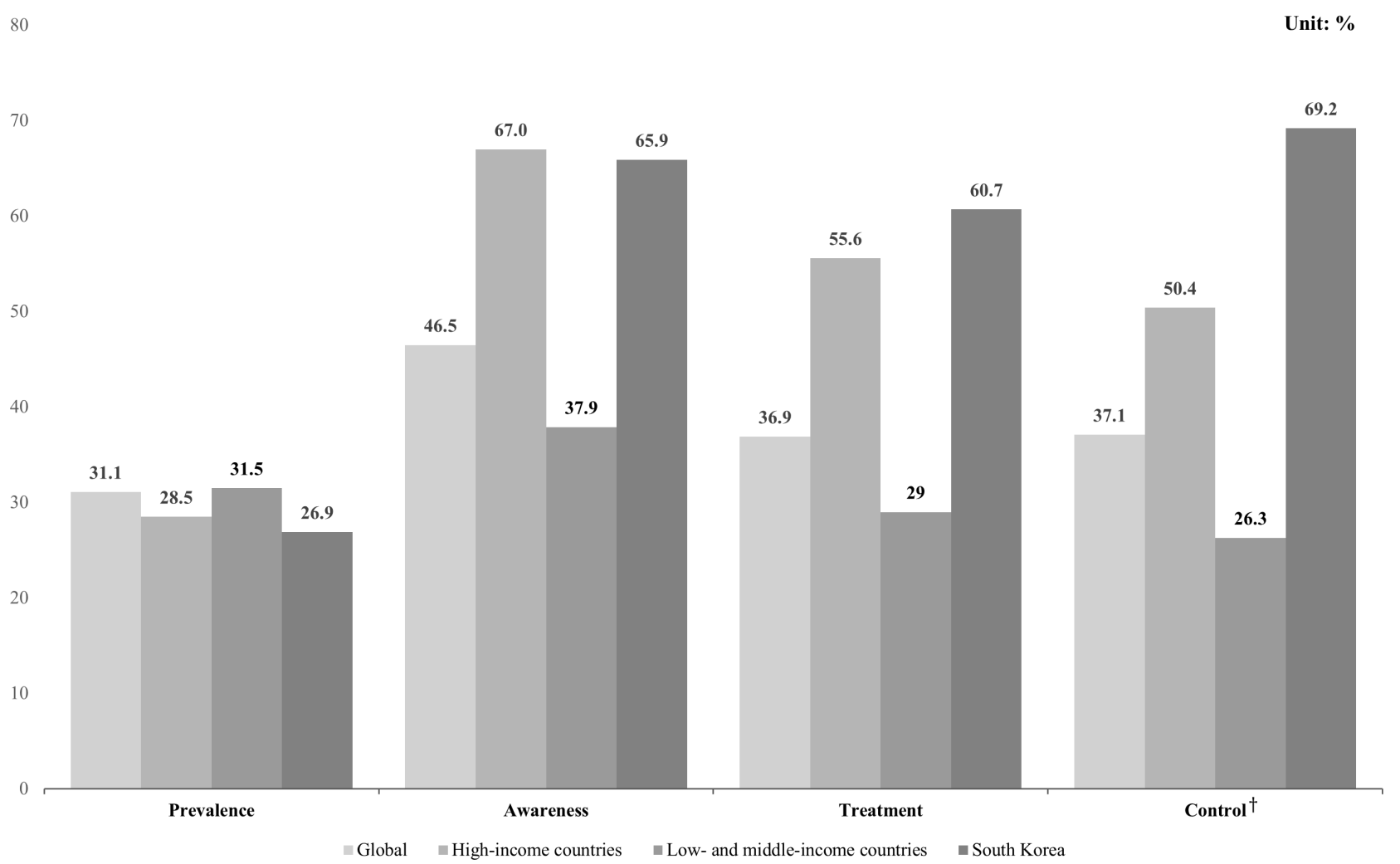

Figure 1 Comparison of hypertension awareness, treatment and control.

follow diets or carry out lifestyle changes as per the advice of their healthcare providers, based on the treatment alliance established between the patient and the healthcare provider. ${ }^{17}{ }^{18}$ Most healthcare providers are unlikely to doubt that the effect of hypertensive treatment may be greater in patients taking their medication as prescribed and conversely less in those who do not. Although low adherence may result from poor blood pressure control in patients with apparent resistant or refractory hypertension, ${ }^{19} 20$ a significant factor contributing to poor blood pressure control is that patients may not adhere to medication therapy as prescribed. ${ }^{21}$

Studies regarding medication adherence and stroke incidence in patients with hypertension have been reported. ${ }^{3} 8918$ 22-24 However, only a few studies evaluating the relationship between medication adherence and health outcomes have been conducted in South Korea. ${ }^{23}$ Therefore, the objective of this study was to investigate the effect of adherence to hypertensive medication on stroke occurrence in South Korea using nationally representative data.

\section{MATERIALS AND METHODS}

\section{Study population}

The South Korea National Health Insurance (NHI) published cohort data, based on data from 2002, with 1025340 representative individuals randomly extracted by stratifying for sex, age, employment status (employed or self-employed), income and individual total medical costs. These data include claim data with details for patient's utilisation of healthcare and check-up data from 2002 to 2013. The current study population included patients with hypertension and aged over 30 years who received a check-up between 2009 and 2013 and had no history of stroke before 2009. Patients with hypertension were defined as patients who visited healthcare organisations with I10-I15 of the International Classification of Diseases groupings (ICD-10) and received a prescription for antihypertensive medication (diuretics: ATC code C03; beta-blocker: ATC code C07; calcium antagonists: ATC code C08; ACE inhibitors and angiotensin antagonists: ATC code C09; and miscellaneous antihypertensive agents: ATC code C02). Patients who had a stroke in the same calendar year as the diagnosis of hypertension were 
excluded. Finally, data of a total of 38520 participants obtained from 1 January 2009 to 31 December 2013 were included in the analysis. This study was approved by the Institutional Review Board, Yonsei University Graduate School of Public Health (2014-239). This study did not seek informed consent from patients as the datasets were completely anonymous and contained no personal information related to the participants.

\section{Measures}

The outcome variable of this study was the incidence of stroke between 1 January 2009 and 31 December 2013. The incidence of stroke during the follow-up period was determined by the first visit record from the time of the stroke (ICD-10: I60-I64). To minimise reverse causation, patients with a history of stroke before 2009 were excluded from the analysis.

The primary variable of interest related to stroke was the adherence to antihypertensive medication, which was measured as the medication possession ratio (MPR). The MPR is based on the ratio of the number of days supplied with medication to the total number of days in the year before the study year. ${ }^{26}$ The MPR in the current study was calculated as follows:

$\mathrm{MPR}=\frac{\text { Number of days supplied by at least one during the year }}{\text { Number of days between first fill and the last day of the year }}$

The MPR was measured annually. The denominator, the number of days between the first prescription and the last day of the calendar year, ranged 1-365. Monotherapy or combination therapy was determined from the first prescription of the year. An MPR of 1 (adherence) indicates that the prescription was supplied on all days of the year. The MPR method is a common measurement of medication adherence using administrative data. ${ }^{27}$ In previous studies, high adherence to medication was defined as MPR $\geq 80 \% .{ }^{28}$ Thus, we categorised adherence to medication as high adherence $(\geq 80 \%)$, intermediate adherence $(50 \%-80 \%)$ and poor adherence $(<50 \%)$.

To analyse the relationship between medication adherence and stroke, we adjusted for the following potential confounders: age, sex, income, region, Charlson Comorbidity Index (CCI), metabolic syndrome, family history of stroke, smoking, regular exercise, type of hypertension, duration of hypertension and year. Age was classified into four groups: 30-49, 50-59, 60-69 and $\geq 70$ years. Region was categorised into urban and rural, and income was estimated using the health insurance premium. Medical aid was defined as not paying health insurance premiums, low income was defined as the bottom $20 \%$ of health insurance premiums, middle income was defined as $20 \%-80 \%$ of the premiums and high income was defined as the top $20 \%$ of premiums. The CCI was used to account for the effects of comorbid disorders or diseases and was calculated per visit based on Quan's methods $^{29} ; 19$ diseases were classified into scores of 1 , 2, 3 or 6 and the CCI was then calculated from the sum of all scores and given extra scores according to age.
Metabolic syndrome was diagnosed according to the revised National Cholesterol Education Program (NCEP) Adult Treatment Panel III criteria ${ }^{30}$. The NCEP criteria suggest that metabolic syndrome meet at least three of the following components: (1) abdominal obesity (waist circumference $\geq 90 \mathrm{~cm}$ for South Korean men or $\geq 85 \mathrm{~cm}$ for South Korean women), (2) triglycerides $\geq 150 \mathrm{mg}$ / dL, (3) high-density lipoprotein cholesterol $\leq 40 \mathrm{mg} / \mathrm{dL}$ for men or $50 \mathrm{mg} / \mathrm{dL}$ for women, (4) systolic/diastolic blood pressure $\geq 130 / 85 / 85 \mathrm{~mm} \mathrm{Hg}$ or (5) fasting plasma glucose $\geq 100 \mathrm{mg} / \mathrm{dL}$. Smoking status was categorised into non-smoker, former smoker and current smoker. Duration of hypertension was classified into the following three groups: within $2,2-5$ and $5-10$ years.

\section{Statistical analysis}

We determined the distribution of each categorical variable by examining frequencies and percentages, and that of the continuous variable by examining means and SD. In addition, Poisson regression using generalised estimating equations (GEE), including confounders and interesting variables, was used to examine the association between stroke during the study period and each variable. Poisson regression is typically used to model rare events, and repeated measures were considered.$^{31}$ Subgroup analyses were also performed to assess whether the effect of medication adherence on stroke incidence depends on the duration of hypertension. Finally, sensitivity analyses were performed by varying the range of MPR. All statistical analyses were performed using SAS statistical software, V. 9.3 (SAS Institute, Cary, North Carolina, USA). All calculated $p$ values were two sided, and a value $<0.05$ was considered statistically significant.

\section{RESULTS}

Among the 38520 patients with hypertension, 957 (2.5\%) strokes occurred during the study period. Table 1 shows the baseline characteristics of the study population. At baseline, patients with hypertension had a mean MPR of $79 \%$. There were $26512(68.8 \%)$ patients with hypertension with high adherence to hypertensive medication. Subjects who were 50-59 years comprised the highest proportion of the study population at 13423 (34.9\%). There were $20870(54.2 \%)$ males and 17649 (45.8\%) females; 17191 subjects $(44.6 \%)$ had a duration of hypertension of $<2$ years.

The results of the Poisson regression with GEE to investigate the relationship between stroke incidence and medication adherence are shown in table 2. Poorer medication adherence was significantly associated with a higher risk of stroke (intermediate adherence: adjusted relative risk $(\mathrm{aRR})=1.13,95 \% \mathrm{CI}(\mathrm{CI})=1.06$ to 1.21 ; poor adherence: $\mathrm{aRR}=1.27,95 \% \mathrm{CI}=1.17$ to 1.38 ; reference: high adherence). Older patients had a higher risk of stroke (50-59 years of age: $\mathrm{aRR}=1.73,95 \% \mathrm{CI}=1.46$ to $2.04 ; 60-69$ years of age: $\mathrm{aRR}=2.90,95 \% \mathrm{CI}=2.39$ to $3.52 ; \geq 70$ years of age: aRR $=4.76,95 \% \mathrm{CI}=3.83$ to 5.93 ; reference: $30-49$ 
Table 1 Baseline characteristics of study population

\begin{tabular}{|c|c|c|}
\hline & N/mean & $\% / \pm S D$ \\
\hline $\begin{array}{l}\text { Medication adherence (medical } \\
\text { possession rate, MPR) }\end{array}$ & 0.79 & \pm 0.29 \\
\hline High adherence (MPR $\geq 0.8)$ & 26512 & 68.8 \\
\hline $\begin{array}{l}\text { Intermediate adherence } \\
(0.5 \leq \mathrm{MPR}<0.8)\end{array}$ & 4996 & 13.0 \\
\hline Poor adherence (MPR<0.5) & 7012 & 18.2 \\
\hline \multicolumn{3}{|l|}{ Age } \\
\hline $30-49$ & 8670 & 22.5 \\
\hline $50-59$ & 13423 & 34.9 \\
\hline $60-69$ & 10468 & 27.2 \\
\hline 70 & 5959 & 15.5 \\
\hline \multicolumn{3}{|l|}{ Sex } \\
\hline Men & 20870 & 54.2 \\
\hline Women & 17649 & 45.8 \\
\hline \multicolumn{3}{|l|}{ Income } \\
\hline Medical aid & 602 & 1.6 \\
\hline Low $(0 \%-20 \%)$ & 6089 & 15.8 \\
\hline Middle (20.1\%-80\%) & 20390 & 52.9 \\
\hline High $(80.1 \%-100 \%)$ & 11439 & 29.7 \\
\hline \multicolumn{3}{|l|}{ Region } \\
\hline Urban & 26620 & 69.1 \\
\hline Rural & 11900 & 30.9 \\
\hline Charlson Comorbidity Index & 1.65 & \pm 1.25 \\
\hline \multicolumn{3}{|l|}{ Metabolic syndrome } \\
\hline Absence & 24543 & 63.7 \\
\hline Presence & 13977 & 36.3 \\
\hline \multicolumn{3}{|l|}{ Family history of stroke } \\
\hline Absence & 35230 & 91.5 \\
\hline Presence & 3290 & 8.5 \\
\hline
\end{tabular}

Number of antihypertensive

medication

\begin{tabular}{|rrr}
\hline One & 29199 & 75.8 \\
\hline More than 1 & 9321 & 24.2 \\
\hline $\begin{array}{lrr}\text { Duration of hypertension (year) } \\
\leq 2\end{array}$ & \\
\hline $2-5$ & 17191 & 44.6 \\
\hline $5-10$ & 8175 & 34.2 \\
\hline Year & 21.2 \\
\hline 2009 & 11272 & \\
\hline 2010 & 9650 & 29.3 \\
\hline 2011 & 6755 & 17.5 \\
\hline 2012 & 6070 & 15.8 \\
\hline 2013 & 4773 & 12.4 \\
\hline Total & 38520 & 100.0 \\
\hline
\end{tabular}

years of age). Women had a lower risk of stroke compared with men ( $\mathrm{aRR}=0.77,95 \% \mathrm{CI}=0.68$ to 0.87 ). A longer duration of hypertension was associated with a higher risk of stroke $(2-5$ years: aRR $=1.16,95 \% \mathrm{CI}=1.09$ to $1.24 ; 5-10$ years: $\mathrm{aRR}=1.44,95 \% \mathrm{CI}=1.30$ to 1.60 ; reference: within 2 years).

We performed a subgroup analysis according to the duration of hypertension (figure 2). A higher MPR was associated with a lower risk of stroke in each category of the duration of hypertension; however, the risk of stroke according to the extent of medication adherence differed with the duration of hypertension. The risk of stroke associated with non-adherence to antihypertensive medication was greater in shorter duration of hypertension. Finally, we conducted an additional sensitivity analysis (see online supplementary 1) and performed an analysis including MPR of $\leq 1.5$ or $\leq 2.0$ and high adherence/ intermediate adherence of $0.7 / 0.4$ or $0.9 / 0.6$. However, results of the repeat sensitivity analysis did not differ from those of the original analysis.

\section{DISCUSSION}

The potential adverse effects of uncontrolled hypertension, such as increased mortality and morbidity, have been described by many previous studies. Adherence to antihypertensive drugs has been shown to be associated with decreased healthcare utilisation, indicating associations with improved clinical outcomes and decreased medical costs. $^{24233}$ This study was designed to evaluate the relationship between antihypertensive medication adherence and stroke incidence in patients with hypertension. In this large-scale, population-based linkage study, patients with hypertension who experienced their first stroke during the follow-up period had a lower adherence to antihypertensive medication. Patients with hypertension with intermediate or poor adherence to antihypertensive medication had a 1.13 times and 1.27 times higher risk of stroke, respectively, than those with high adherence.

Our findings are consistent with previous investigations reporting a higher adherence to antihypertensive drugs as being associated with a lower risk of adverse outcomes. ${ }^{22}$ A cohort study from Canada found that high adherence (MPR $\geq 80 \%)$ to antihypertensive drugs decreased the risk of cerebrovascular disease by $22 \%$ compared with those with lower adherence. ${ }^{9}$ Pittman et $a l$ also reported that patients with non-adherence to antihypertensive medication (MPR $<80 \%$ ) had a $33 \%$ higher risk of cerebrovascular disease-related hospitalisation and a $45 \%$ higher risk of emergency department visits than those with higher adherence. ${ }^{34}$ Furthermore, according to a study from South Korea, non-adherence to antihypertensive medication (MPR $<80 \%)$ increased the risk of adverse outcomes, including all-cause mortality and hospitalisation for cerebrovascular disease, by $57 \%^{23}$

Unlike other studies, we considered the relationship between the duration of hypertension, medication adherence and index stroke. Non-adherence to antihypertensive 
Table 2 Results of Poisson regression with generalised estimating equations to investigate the relationship between stroke incidence and medication adherence

\begin{tabular}{|c|c|c|c|}
\hline \multirow[b]{2}{*}{ Variables } & \multicolumn{3}{|l|}{ Stroke } \\
\hline & Adjusted RR & $95 \% \mathrm{Cl}$ & p Value \\
\hline \multicolumn{4}{|c|}{ Medication adherence (medical possession rate, MPR) } \\
\hline High adherence (MPR $\geq 0.8$ ) & 1.00 & - & \\
\hline Intermediate adherence $(0.5 \leq \mathrm{MPR}<0.8)$ & 1.13 & 1.06 to 1.21 & 0.0004 \\
\hline Poor adherence (MPR<0.5) & 1.27 & 1.17 to 1.38 & $<0.0001$ \\
\hline \multicolumn{4}{|l|}{ Age } \\
\hline $30-49$ & 1.00 & - & \\
\hline $50-59$ & 1.73 & 1.46 to 2.04 & $<0.0001$ \\
\hline $60-69$ & 2.90 & 2.39 to 3.52 & $<0.0001$ \\
\hline 70 & 4.76 & 3.83 to 5.93 & $<0.0001$ \\
\hline \multicolumn{4}{|l|}{ Sex } \\
\hline Men & 1.00 & - & \\
\hline Women & 0.77 & 0.68 to 0.87 & $<0.0001$ \\
\hline \multicolumn{4}{|l|}{ Income } \\
\hline Medical aid & 1.39 & 0.93 to 2.06 & 0.1049 \\
\hline Low $(0 \%-20 \%)$ & 1.00 & - & \\
\hline Middle (20.1\%-80\%) & 0.94 & 0.87 to 1.03 & 0.1741 \\
\hline High $(80.1 \%-100 \%)$ & 0.98 & 0.88 to 1.09 & 0.7204 \\
\hline \multicolumn{4}{|l|}{ Region } \\
\hline Urban & 1.00 & - & \\
\hline Rural & 1.22 & 1.10 to 1.35 & 0.0002 \\
\hline Charlson Comorbidity Index & 1.05 & 1.01 to 1.09 & 0.0081 \\
\hline \multicolumn{4}{|l|}{ Metabolic syndrome } \\
\hline Absence & 1.00 & - & \\
\hline Presence & 1.09 & 1.03 to 1.14 & 0.0016 \\
\hline \multicolumn{4}{|l|}{ Family history of stroke } \\
\hline Absence & 1.00 & - & \\
\hline Presence & 1.13 & 1.03 to 1.24 & 0.0110 \\
\hline \multicolumn{4}{|l|}{ Number of antihypertensive medication } \\
\hline One & 1.00 & - & \\
\hline More than 1 & 1.03 & 0.97 to 1.10 & 0.3651 \\
\hline \multicolumn{4}{|l|}{ Duration of hypertension (year) } \\
\hline$\leq 2$ & 1.00 & & \\
\hline $2-5$ & 1.16 & 1.09 to 1.24 & $<0.0001$ \\
\hline $5-10$ & 1.44 & 1.30 to 1.60 & $<0.0001$ \\
\hline \multicolumn{4}{|l|}{ Year } \\
\hline 2009 & 1.00 & - & \\
\hline 2010 & 2.58 & 2.39 to 2.77 & $<0.0001$ \\
\hline 2011 & 1.99 & 1.86 to 2.12 & $<0.0001$ \\
\hline 2012 & 1.66 & 1.58 to 1.73 & $<0.0001$ \\
\hline 2013 & 1.25 & 1.17 to 1.33 & $<0.0001$ \\
\hline
\end{tabular}

$\mathrm{RR}$, relative risk. 


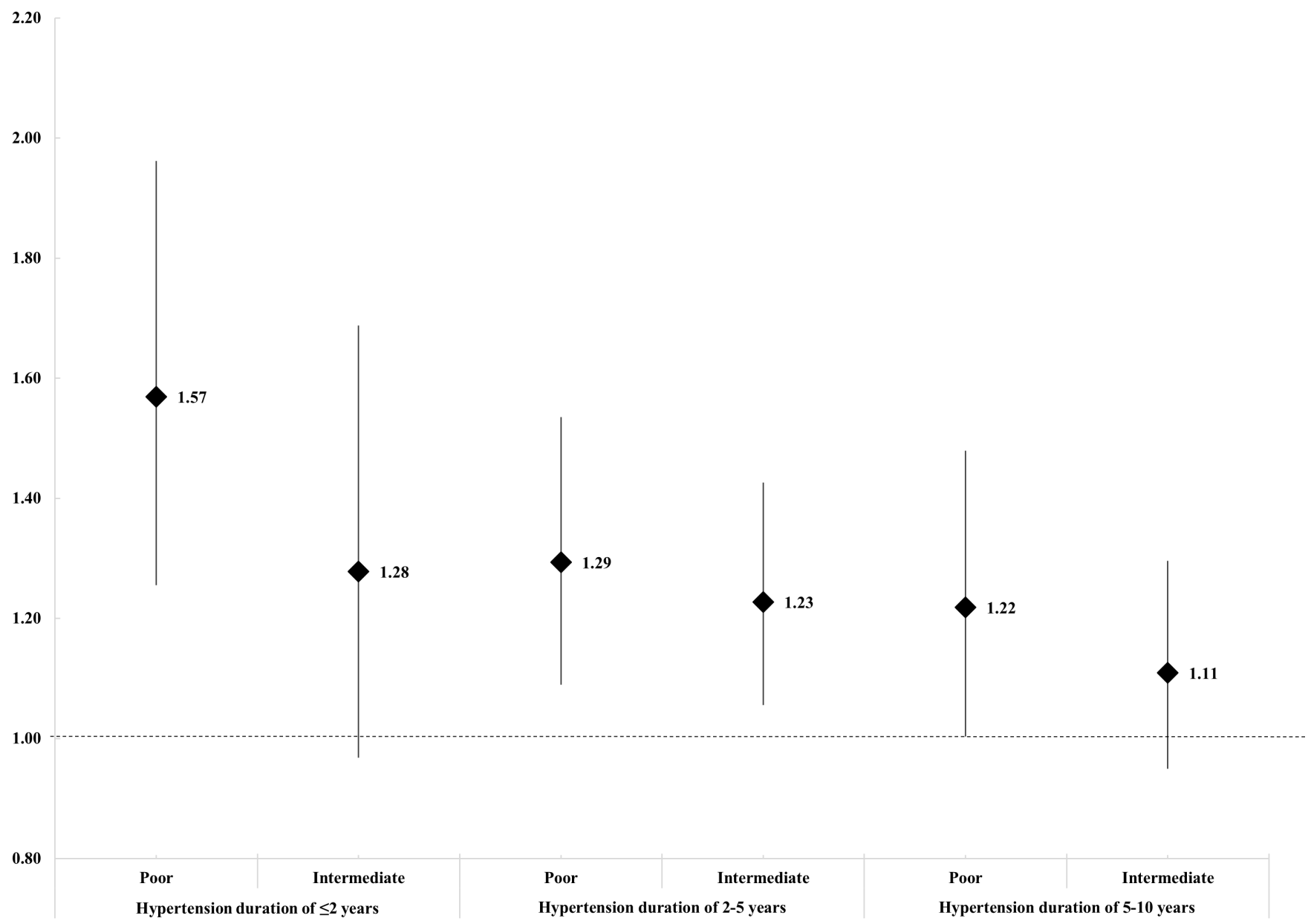

Figure 2 Results of Poisson regression with general estimating equations to investigate the relationship between stroke and medication adherence according to duration of hypertension. The relative risk (RR) (black diamond) was calculated by Poisson regression analysis adjusted for all covariates, and results were considered statistically significant if each bar, as marked to standard deviation SD, did not reach the cut-off line of 1.00 .

medication in patients with hypertension was associated with an increased risk of stroke according to the duration of hypertension. The risk of stroke associated with non-adherence to antihypertensive medication was greater in patients with shorter duration of hypertension. A previous study reported similar findings; with patients with non-adherence to medication having 3.81 and 3.01 times higher odds of death caused by stroke compared with patients with adherence to medication at the 2 and 10-year follow-up, respectively, after patients were diagnosed with hypertension and started taking medication. ${ }^{3}$ However, our results need to be carefully interpreted and further research is needed because these results might be related to differences in intended or unintended discontinuation of antihypertensive therapy. ${ }^{35}$

Non-adherence to medication in patients with hypertension is a significant but often unrecognised risk factor for poor blood pressure control, and thus results in the development of further adverse consequences such as morbidity, unexpected hospitalisation and mortality. ${ }^{36}$
In general, non-adherence to medication results from patient or drug-related factors. Drug-related factors include the number of drug types, dosing schedules or side effects of medications, and patient-related factors include forgetting to take medications, lack of awareness of illness and drugs, false beliefs or the lack of economic power. ${ }^{37}$ Because adherence to medication is influenced by various factors, most methods to improve it involve combinations of behavioural interventions and reinforcements in addition to improving communication between physicians and patients, providing educational information about patient condition and treatment, and other forms of supervision or attention. ${ }^{33}$ Once healthcare providers identify patients with hypertension who do not or may not adhere to medication by patient interviews or applying instruments such as the Beliefs about Medicines Questionnaire, they need to assess the reasons for non-adherence to medication and seek ways to improve adherence. Furthermore, adherence to medication and stroke incidence in older and male patients need to be 
monitored more carefully because age and sex are risk factors for stroke, as shown in some studies including the present one. ${ }^{738}$ In South Korea, the incidence of stroke almost doubles for every 10 years after the age of 55 , and men have a $25 \%-30 \%$ higher incidence of stroke than women. ${ }^{38}$

This study had several limitations related to limited data and methodological issues. First, we indirectly measured antihypertensive medication adherence based on administrative claim data. There are many different methods of measuring medication adherence both directly and indirectly. In direct methods, researchers directly assess the amount of medication taken; however, these methods are limited by the potential for patient dishonesty. In contrast, analysing body fluids for drugs and metabolites, another direct method to assess adherence to medication does not rely on patient honesty. However, direct methods are time consuming or more expensive than indirect methods. In contrast, the MPR method, an indirect method using claim data, does not depend on whether patients actually take their medication as prescribed, but depends on the prescription given by physicians. Thus, the MPR method may overestimate the amount actually consumed. Nevertheless, this method is a well-validated tool and is useful for measuring adherence to medication over a long period of time. Meanwhile, proportion of days covered (PDC) is another indirect method of measuring adherence to medication using claim data. PDC is defined as the proportion of days in the measurement period 'covered', not 'supplied', by prescription claims for the same medication or another in its therapeutic category. ${ }^{39}$ We applied the MPR method in our study instead of the PDC because we did not consider the type of prescription drug; that is, cases where patients switched medications during a calculation interval were not identified. Next, the use of claim data may have affected the validity of the results of this study. However, we do not expect this limitation to pose a meaningful threat to the validity of our results. Previous study reported that the accuracy of the stroke diagnosis code in the claim data of Korea is over $80 \% .{ }^{40}$ In addition, we defined patients with hypertension as only those who were diagnosed with hypertension and who were prescribed antihypertensive drugs. Finally, this study may have selection bias, as check-ups in South Korea could be offered by NHI and private hospitals. We included only patients with hypertension who received a check-up from the NHI in this study analysis.

Nevertheless, this study has advantages over similar previous studies. Our data included check-up data as well as administrative data; thus, we were able to adjust for some potential confounders, such as family history of stroke and economic status. ${ }^{41}$ Next, to our knowledge, this is the first study in South Korea to consider the duration of hypertension and changes in adherence prior to a stroke in relation to adherence to antihypertensive medication and index stroke.

In conclusion, adherence to antihypertensive medication in patients with hypertension is associated with a decreased risk of stroke over the duration of hypertension. The preventive effect of adherence to antihypertensive medication on risk of stroke is greater as the duration of hypertension shortens. Medication adherence is a key factor in determining the success of antihypertensive therapy and primary prevention of stroke. Therefore, the findings of this study indicate that healthcare providers need to perform intervention strategies to ensure adherence to medication therapy after patients are diagnosed with hypertension, and continue to support patients to achieve long-term adherence, ultimately minimising negative health outcomes.

Contributors HJL designed the study, performed statistical analyses and wrote the manuscript. HJL, S-IJ and E-CP contributed to the Discussion section and reviewed and edited the manuscript. E-CP is the guarantor of this work and, as such, has full access to all the data in the study and takes responsibility for the integrity of the data and the accuracy of the data analysis. The English in this document has been checked by at least two professional editors, both native English speakers.

Competing interests None declared.

Patient consent We used encrypted data from which personal information could not be identified.

Ethics approval The Institutional Review Board, Yonsei University Graduate School of Public Health.

Provenance and peer review Not commissioned; externally peer reviewed.

Data sharing statement The data are available from the Korean National Health Insurance Service (NHIS), but access to confidential data is limited to researchers who meet the necessary criteria; basically, any researcher who proposes a study subject and plans with a standardised proposal form and are approved by the NHIS review committee on research support can access the raw data. Details of this process and a provision guide are now available at http://nhiss.nhis.or.kr/bd/ab/ bdaba000eng.do.

Open Access This is an Open Access article distributed in accordance with the Creative Commons Attribution Non Commercial (CC BY-NC 4.0) license, which permits others to distribute, remix, adapt, build upon this work non-commercially, and license their derivative works on different terms, provided the original work is properly cited and the use is non-commercial. See: http://creativecommons.org/ licenses/by-nc/4.0/

(C) Article author(s) (or their employer(s) unless otherwise stated in the text of the article) 2017. All rights reserved. No commercial use is permitted unless otherwise expressly granted.

\section{REFERENCES}

1. World Health Organization. The top 10 causes of death. 2012 http:// www.who.int/mediacentre/factsheets/fs310/en/index1.html2016.

2. Statistics Korea. All cause of mortality. 2014 https://kostat.go.kr/ portal/korea/kor_nw/2/6/2/index.board2016.

3. Herttua K, Tabák AG, Martikainen P, et al. Adherence to antihypertensive therapy prior to the first presentation of stroke in hypertensive adults: population-based study. Eur Heart $J$ 2013;34:2933-9.

4. Kinlay S. Changes in stroke epidemiology, prevention, and treatment. Circulation 2011;124:e494-e96.

5. Park TH, Jang MS, Yang MH, et al. Prestroke medication adherence and its clinical significance in patients with ischemic stroke: single hospital-based study. J Korean Neurol Assoc 2010;28:270-6.

6. Perreault S, Yu AY, Côté R, et al. Adherence to antihypertensive agents after ischemic stroke and risk of cardiovascular outcomes. Neurology 2012;79:2037-43.

7. Clinical Research Center for Stroke. Clinical practice guidelines for stroke. 2013 http://www.stroke-crc.or.kr/\%EB\%87\%8C\%EC\%A1\% B8\%EC\%A4\%91\%EC\%A7\%84\%EB\%A3\%8C\%EC\%A7\%80\% EC\%B9\%A8\%2020130322.pdf.

8. Mazzaglia G, Ambrosioni E, Alacqua M, et al. Adherence to antihypertensive medications and cardiovascular morbidity among newly diagnosed hypertensive patients. Circulation 2009;120:1598-605. 
9. Kettani FZ, Dragomir A, Côté R, et al. Impact of a better adherence to antihypertensive agents on cerebrovascular disease for primary prevention. Stroke 2009;40:213-20.

10. Chow CK, Teo KK, Rangarajan S, et al. Prevalence, awareness, treatment, and control of hypertension in rural and urban communities in high-, middle-, and low-income countries. JAMA 2013;310:959-68.

11. James PA, Oparil S, Carter BL, et al. 2014 evidence-based guideline for the management of high blood pressure in adults: report from the panel members appointed to the Eighth Joint National Committee (JNC 8). JAMA 2014;311:507-20.

12. Whitworth JA; World Health Organization, International Society of Hypertension Writing Group. 2003 World Health Organization (WHO)/International Society of hypertension (ISH) statement on management of hypertension. J Hypertens 2003;21:1983-92.

13. The Korean Society of Hypertension. Hypertension management guidelines. 2013 www.koreanhypertension.org/download/131107_01. pdf

14. Korean Academy of Medical Sceiences, Korean Centers for Disease Control and Prevention. High blood pressure recommendation manual for primary care, 2015.

15. Mills KT, Bundy JD, Kelly TN, et al. Global disparities of hypertension prevalence and ControlClinical Perspective. Circulation 2016;134:441-50.

16. Ministry of Health \& Welfare. National health statistics in 2010, 2012.

17. Horwitz RI, Horwitz SM. Adherence to treatment and health outcomes. Arch Intern Med 1993;153:1863-8.

18. Wu PH, Yang CY, Yao ZL, et al. Relationship of blood pressure control and hospitalization risk to medication adherence among patients with hypertension in Taiwan. Am J Hypertens 2010;23:155-60.

19. Jung O, Gechter JL, Wunder C, et al. Resistant hypertension? assessment of adherence by toxicological urine analysis. $J$ Hypertens 2013;31:766-74.

20. Gupta P, Patel P, Horne R, et al. How to screen for non-adherence to antihypertensive therapy. Curr Hypertens Rep 2016;18:89.

21. Krousel-Wood M, Thomas S, Muntner P, et al. Medication adherence: a key factor in achieving blood pressure control and good clinical outcomes in hypertensive patients. Curr Opin Cardiol 2004;19:357-62.

22. Degli Esposti L, Saragoni S, Benemei S, et al. Adherence to antihypertensive medications and health outcomes among newly treated hypertensive patients. Clinicoecon Outcomes Res 2011;3:47-54.

23. Shin S, Song H, Oh SK, S-k O, et al. Effect of antihypertensive medication adherence on hospitalization for cardiovascular disease and mortality in hypertensive patients. Hypertens Res 2013;36:1000-5.

24. Bailey JE, Wan JY, Tang J, et al. Antihypertensive medication adherence, ambulatory visits, and risk of stroke and death. J Gen Intern Med 2010;25:495-503.

25. Kim S, Shin DW, Yun JM, et al. Medication adherence and the risk of cardiovascular mortality and hospitalizationaAmong patients
With newly prescribed antihypertensive medications. Hypertension 2016;67:506-12

26. Hong JS, Kang HC. Relationship between oral antihyperglycemic medication adherence and hospitalization, mortality, and healthcare costs in adult ambulatory care patients with type 2 diabetes in South Korea. Med Care 2011;49:378-84.

27. Halpern MT, Khan ZM, Schmier JK, et al. Recommendations for evaluating compliance and persistence with hypertension therapy using retrospective data. Hypertension 2006;47:1039-48.

28. Karve S, Cleves MA, Helm M, et al. Good and poor adherence: optimal cut-point for adherence measures using administrative claims data. Curr Med Res Opin 2009;25:2303-10.

29. Charlson ME, Pompei P, Ales KL, et al. A new method of classifying prognostic comorbidity in longitudinal studies: development and validation. J Chronic Dis 1987;40:373-83.

30. Grundy SM, Cleeman JI, Daniels SR, et al. Diagnosis and management of the metabolic syndrome: an American Heart Association/National Heart, Lung, and Blood Institute Scientific Statement. Circulation 2005;112:2735-52.

31. Stewart WF, Lipton RB, Liberman J. Variation in migraine prevalence by race. Neurology 1996;47:52-9.

32. Kaddumukasa M, Ddumba E, Duncan $P$, et al. Poststroke hypertension in Africa. Stroke 2012;43:3402-4.

33. Osterberg L, Blaschke T. Adherence to medication. N Engl J Med 2005;353:487-97.

34. Pittman DG, Tao Z, Chen W, et al. Antihypertensive medication adherence and subsequent healthcare utilization and costs. Am J Manag Care 2010;16:568-76.

35. Schulz M, Krueger K, Schuessel K, et al. Medication adherence and persistence according to different antihypertensive drug classes: a retrospective cohort study of 255,500 patients. Int J Cardiol 2016;220:668-76.

36. Munger MA, Van Tassell BW, LaFleur J. Medication nonadherence: an unrecognized cardiovascular risk factor. MedGenMed 2007;9:58-91.

37. Ahn YH. Effects of an integrated case management program on medication adherence, pain, physical function and depression among Korean medical aid beneficiaries with osteoarthritis. J Korean Public Health Nurs 2014;28:32-45.

38. Regional Cardiovascular Disease Center of Kyung Book National University Hospital. Types and risk factors for stroke, 2009.

39. Pm H, Bryson CL, Rumsfeld JS. Medication adherence. Circulation 2009;119:3028-35.

40. Kim JH, Cho BM, Hwang IK, et al. Trends of health care utilization and relevance index of stroke inpatients among the self-employed insured and their dependents of National Health Insurance (1998-2005). Korean J Health Policy \& Administration 2008;18:66-84

41. Padwal R, Straus SE, McAlister FA. Evidence based management of hypertension. cardiovascular risk factors and their effects on the decision to treat hypertension: evidence based review. BMJ 2001;322:977-80. 